\title{
PENERAPAN SEO (SEARCH ENGINE OPTIMIZATION) MENGGUNAKAN TEKNIK TOGETHER IN A SINGLE CONNECTION (TSC) DALAM MENINGKATKAN KUNJUNGAN PADA SEBUAH BLOG
}

\author{
Devia Tito Setyaningsih, Hero Wintolo, Dwi Nugraheny \\ Teknik Informatika STTA Yogyakarta \\ informatika@stta.ac.id
}

\begin{abstract}
One of the internet service used by the people of Indonesia is a blog that can be accessed via http://ologspot.com or http://wordpress.com and others. Everyone can use this medium for the purpose of publication of information in the form of text, images, sounds, or video without having to master web programming languages. One of the obstacles a person who has a blog is a way of increasing number of visitors to his blog. In order for many visitors the blog owner needs to understand about SEO (Search Engine Optimization).

To allow users to blog in increasing the number of visitors and ranking his blog, they invented a system that utilizes parallel processing techniques and create a new method, named TSC (Together in a Single Connection) to increase the number of visitors, number of pages viewed and ranking.

Increase blog traffic system based on parallel processing can improve the effectiveness in increasing traffic to a blog. With this system the blog owner is expected to be easier to rise to visit his blog.
\end{abstract}

Keywords: SEO, TSC, Blog Visitation.

\section{Latar Belakang Masalah}

Salah satu layanan internet yang digunakan oleh masyarakat Indonesia adalah blog yang

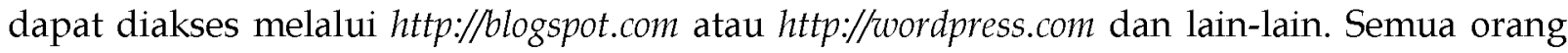
dapat menggunakan media ini untuk kepentingan publikasi berbagai informasi baik dalam bentuk teks, gambar, suara, atau video tanpa harus menguasai bahasa pemrograman web. Salah satu kendala seseorang yang memiliki blog adalah cara meningkatkan jumlah pengunjung blog-nya. Agar banyak pengunjungnya maka pemilik blog tersebut perlu memahami tentang SEO (Search Engine Optimization).

SEO merupakan serangkaian proses yang dilakukan secara sistematis yang bertujuan untuk meningkatkan volume dan kualitas trafik dari mesin pencari menuju alamat situs web tertentu dengan memanfaatkan mekanisme kerja alami algoritma mesin pencari tersebut. Tujuan SEO adalah menempatkan suatu alamat situs web pada posisi teratas (atau setidaknya pada halaman pertama) hasil pencarian berdasarkan subyek tertentu. Secara logis, alamat situs yang menempati posisi teratas hasil pencarian memiliki peluang lebih besar untuk mendapatkan banyak pengunjung. Teknik SEO sangat penting sekali dalam dunia internet karena tidak dapat dipungkiri, bahwa dengan menjadi urutan teratas sebuah website akan semakin diminati oleh para pengguna Internet. Pengunjung cenderung lebih tertarik dengan beberapa website yang ada di halaman awal karena dianggap lebih relevan dengan keyword 
yang dicari. Dari kecenderungan tersebut, maka dapat menarik peminat para pengguna internet untuk berkunjung ke website tersebut. Teknik SEO terdapat beberapa macam, antara lain memasang breadcrump, dummy blog, on page dan off page, memasang meta tag, dan membuat judul SEO yang friendly. Breadcrump merupakan menu navigasi untuk pengunjung dalam pencarian artikel dan kembali lagi ke home page dengan mudah, sedangkan dummy blog adalah salah satu cara untuk optimasi blog agar bisa masuk dan punya peringkat bagus di mesin pencari. Istilah lain dari teknik SEO adalah memasang meta tag, maksudnya agar blog mudah dibaca oleh mesin pencari semacam google. Sedangkan, membuat judul SEO yang friendly adalah judul SEO dapat dengan mudah dicari oleh pengguna internet.

Selain teknik SEO diatas, dalam tugas akhir ini menggunakan teknik yang diberi nama Together in a Single Connection (atau disingkat dengan TSC), merupakan sebuah cara untuk meningkatkan kunjungan pada sebuah blog dengan memanfaatkan teknik pemrosesan paralel yang dikendalikan oleh komputer server dengan membuka blog setiap hari dengan alamat internet protocol (IP) yang berbeda-beda menggunakan media penghubung internet (modem). Dengan cara ini diharapkan jumlah visitor dan page view dari sebuah blog dapat meningkat, sehingga blog tersebut akan meningkat ranking-nya di search engine.

\section{Blog}

Istilah blog merupakan bentuk singkat dari weblog atau web log. Blog pada dasarnya adalag sebuah jurnal online yang tersedia atau disediakan di web (blog). Menurut pakar blog, a blog is a type of website that is usually arranged in chronological order from the most recent 'post' (or entry) at the top of the main page to the older entries towards the bottom (Darren Rowse). Jadi, sebuah blog adalah sejenis website yang biasanya diatur dalam urutan kronologis dari 'post' paling baru (atau entry) di bagian atas halaman utama ke entri yang lebih lama ke arah bawah. Orang yang menulis atau melakukan entri data dalam sebuah blog disebut dengan "blogger", sedangkan aktifitas yang dilakukan untuk memelihara sebuah blog atau menambah artikel (content) ke sebuah blog disebut "blogging". Sebuah blog memiliki banyak manfaat, diantaranya adalah untuk bisnis, untuk menyalurkan kegemaran menulis, untuk pendidikan, untuk menerbitkan jurnal, dan lain sebagainya.

\section{a. SEO (Search Engine Optimization)}

SEO merupakan sebuah proses yang digunakan untuk mengoptimalkan dan memaksimalkan halaman blog untuk pencarian dalam mesin pencari. Proses tersebut merupakan sebuah teknik pemasaran internet yang ditujukan untuk meningkatkan trafik kunjungan dalam sebuah konten jaringan dan meningkatkan kualitas trafik sendiri. Beberapa teknik SEO sudah banyak yang digunakan oleh pemilik blog. Sedangkan di tugas akhir ini memperkenalkan teknik baru SEO, yang diberi nama teknik TSC (Together in a Single Connection). Teknik ini akan dibangun dan dibahas dalam penyusunan tugas akhir ini. Pembukaan alamat web akan dilakukan secara berulang-ulang sampai halaman web mencapai 10 halaman web. Satu halaman web diberi timer selama 20 detik untuk membuka utuh halaman web tersebut. Apabila sudah mencapai 20 detik, maka client akan membuka halaman web yang lain setiap 20 detik. 


\section{b. Layanan Hitstats}

Histats merupakan sebuah situs yang menyediakan dan menampilkan informasi lengkap tentang pengunjung dan tampilan halaman, serta menampilkan seluruh informasi rinci tentang lalu lintas situs web dan hasilnya digunakan untuk mengembangkan rencana pemasaran yang tepat. Layanan histats juga menawarkan layanan gratis yang lengkap dan real time. Selain itu, histats dalam sebuah blog menampilkan jumlah pengunjung yang online, jumlah pengunjung dalam sehari, jumlah pengunjung yang aktif membuka blog, menampilkan halaman populer di blog tersebut, dan informasi lainnya.

\section{c. Pemrograman Socket Delphi}

Socket adalah mekanisme komunikasi yang memungkinkan terjadinya pertukaran data antar program atau proses baik dalam satu mesin maupun antar mesin. Salah satu elemen penting yang digunakan dalam aplikasi socket adalah port. Port merupakan sebuah koneksi data virtual yang digunakan oleh sebuah aplikasi untuk bertukar data secara langsung. Terdapat banyak port di dalam sebuah sistem komputer dengan fungsinya masing-masing.

Dalam tugas akhir ini, komponen socket yang dipakai adalah ServerSocket dan ClientSocket yng terdapat di library Internet. Masing-masing socket memiliki nomor port yang berbeda-beda, sedangkan untuk menghubungkan koneksi serversocket dan clientsocket mempunyai nomor port yang sama.

\section{d. Together in a Single Connection (TSC)}

TSC merupakan salah satu teknik dalam meningkatkan page view dan visitor sebuah blog. Teknik TSC memanfaatkan 2 (dua) atau lebih komputer client yang merupakan sebuah perangkat yang menerima yang akan menampilkan dan menjalankan aplikasi (software komputer), sedangkan sebuah komputer server adalah perangkat yang menyediakan dan bertindak sebagai pengelola aplikasi, data, dan keamanannya. Komputer server dan client terhubung dengan teknik pemrosesan paralel, yaitu dengan mengirim alamat blog dari komputer server ke komputer client setiap hari menggunakan sebuah koneksi (modem), sehingga akan mempunyai alamat IP yang berbeda-beda setiap koneksi dihubungkan. Gambar 1 merupakan gambaran dari aplikasi yang akan dibangun menggunakan 5 (lima) aplikasi client.

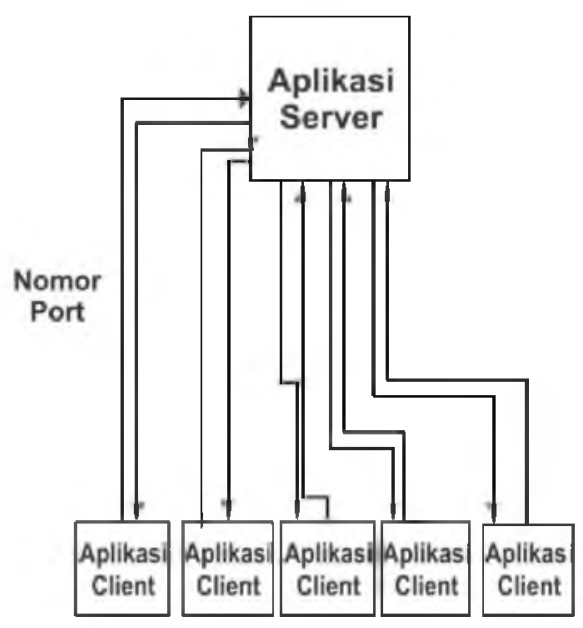

Gambar 1 Gambaran Aplikasi Menggunakan 5 Aplikasi Client 


\section{Penjelasan Aplikasi Menggunakan Metode TSC (Together in a Single Connection)}

Aplikasi yang dibangun ini menggunakan metode TSC. Metode TSC merupakan sebuah metode yang berjalan atau melakukan proses dalam sebuah koneksi yang sama. Proses yang berjalan dalam satu koneksi dan berjalan secara bersama-sama dan berulang-ulang.

Secara umum, aplikasi ini merupakan aplikasi client-server. Aplikasi yang terdiri dari aplikasi client dan aplikasi server. Aplikasi ini merupakan aplikasi yang digunakan untuk mengirim data dari server ke client. Data yang dikirimkan berupa halaman web yang berjumlah 10. Sepuluh halaman web tersebut dikirim secara bersama-sama dalam sebuah koneksi yang sama dan dikirim 20 detik sekali setiap halaman web-nya.

\section{Konfigurasi Jaringan}

Untuk menjalankan aplikasi ini harus dilakukan konfigurasi jaringan terlebih dahulu. Peralatan yang dibutuhkan yaitu sebuah komputer yang digunakan sebagai server dan 3 unit komputer yang digunakan sebagai client. Digunakan switch untuk menyatukan kabel-kabel yang terhubung antara komputer server dan beberapa komputer client. Modem dihubungkan dengan komputer client sebagai pembuka pesan. Gambaran dari konfigurasi jaringan yang digunakan pada aplikasi ini dapat dilihat pada gambar 2.

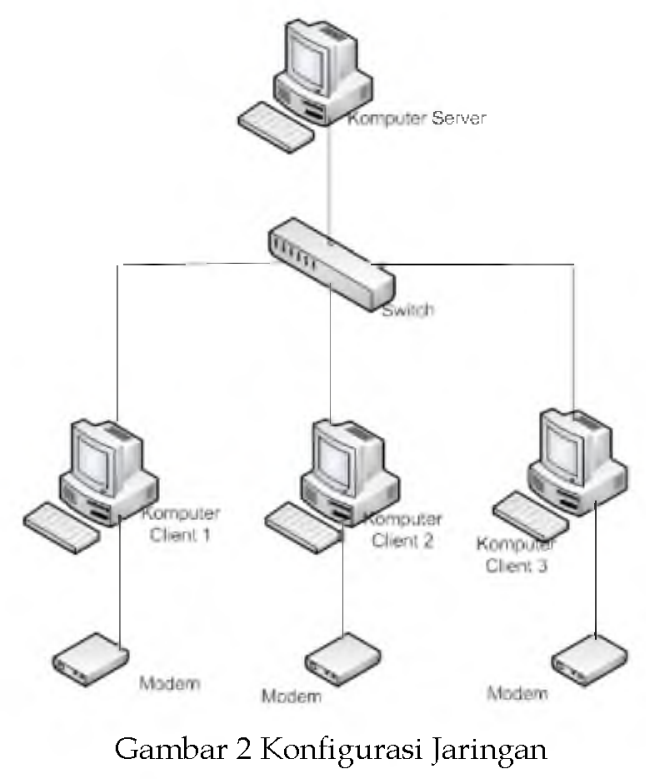

\section{Pengujian Aplikasi}

Uji coba aplikasi ini dilakukan di laboratorium komputer STTA Yogyakarta. Hal ini dikarenakan karena STTA mempunyai komputer dalam jumlah yang banyak yang dapat mendukung jalannya aplikasi ini. Uji coba dilakukan menggunakan 4 buah unit komputer yang telah terhubung dalam suatu jaringan dengan bentuk topologi seperti yang tergambar dalam konfigurasi jaringan. Dari beberapa unit komputer tersebut, satu unit komputer bertindak sebagai server dan yang lain bertindak sebagai client. Tabel 1 menggambarkan beberapa nama komputer dan alamat IP yang terdapat di STTA Yogyakarta yang dapat digunakan sebagai komputer yang bertindak sebagai client. 
Tabel 1 Daftar Nama Komputer untuk Uji Coba

\begin{tabular}{|c|c|}
\hline Nama Komputer & Alamat IP \\
\hline PC Server & 198.168 .5 .250 \\
\hline PC Client 1 & 198.168 .5 .251 \\
\hline PC Client 2 & 198.168 .5 .252 \\
\hline PC Client 3 & 198.168 .5 .253 \\
\hline
\end{tabular}

\section{Uji Coba Penerimaan Pesan Oleh Client}

Dalam uji coba penerimaan pesan oleh client, aplikasi server dan aplikasi client harus terkoneksi terlebih dahulu, dengan menyamakan nomor port untuk kedua aplikasi tersebut sebagai jalur komunikasi dan aplikasi client harus mengisikan nomor IP komputer server. Setelah kedua aplikasi terkoneksi, maka pesan yang dikirimkan oleh seseorang yang ditujukan kepada aplikasi client dapat ditampilkan, sebelum pesan tersebut tampil di aplikasi client, pesan melewati aplikasi server. Pesan yang ditampilkan dalam apilkasi client merupakan sebuah halaman web yang dibuka di browser yang dibangun di aplikasi client. Pesan yang dikirim ke client telah melewati server dengan membaca string pesan sebelum spasi yang menunjukkan tujuan client. Seperti ditunjukan pada gambar 4.10 bahwa pesan tersebut dikirimkan ke client yang bernama PC Client, sedangkan string pesan setelah spasi merupakan isi dari pesan. Dalam uji coba ini digunakan beberapa buah komputer client yang dikirimi pesan yang sama, dan aplikasi client dapat menerima semua pesan yang dikirimkan. Hal ini digambarkan pada tabel 2. Gambar dari aplikasi client yang menerima pesan ditunjukkan seperti pada gambar 3 .

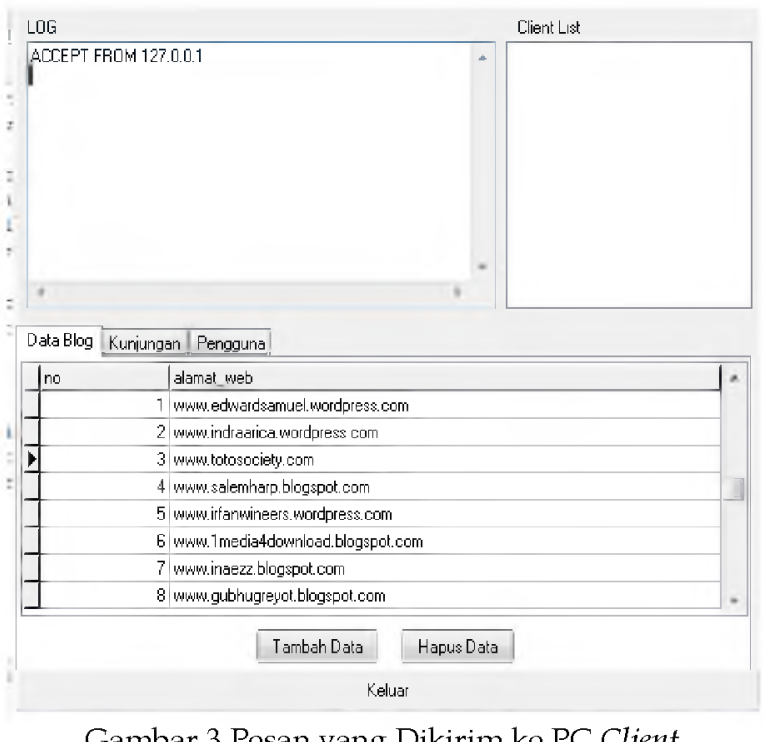

Tabel 2 Uji Menerima Pesan

\begin{tabular}{|c|c|c|c|}
\hline No & Nama Komputer Client & Diterima & Tidak Diterima \\
\hline 1 & PC Client 1 & $\sqrt{ }$ & - \\
\hline 2 & PC Client 2 & $\sqrt{ }$ & - \\
\hline 3 & PC Client 3 & $\sqrt{ }$ & - \\
\hline
\end{tabular}


Dari tabel 2 uji menerima pesan, dapat diketahui bahwa komputer client yang telah dilakukan uji coba, yaitu PC Client dan lainnya berhasil menerima pesan yang dikirimkan oleh pengguna. Dari beberapa kali uji coba yang dilakukan di beberapa komputer client, semua pesan yang dikirimkan dapat diterima, dan tidak ada pesan yang gagal diterima oleh aplikasi client. Tabel 2 menjelaskan bahwa tanda centapgde tabel diterima menggambarkan bahwa PC Client 1, 2 dan 3 sudah menerima data dari server. Gambar 4 merupakan gambar yang berkaitan dengan gambar 3 sebelumnya, yaitu menjelaskan aplikasi client saat menerima pesan dari server. Selanjutnya pesan tersebut akan tertampil di edit text dan pesan yang berupa halaman web tersebut akan dibuka di browser milik aplikasi client.

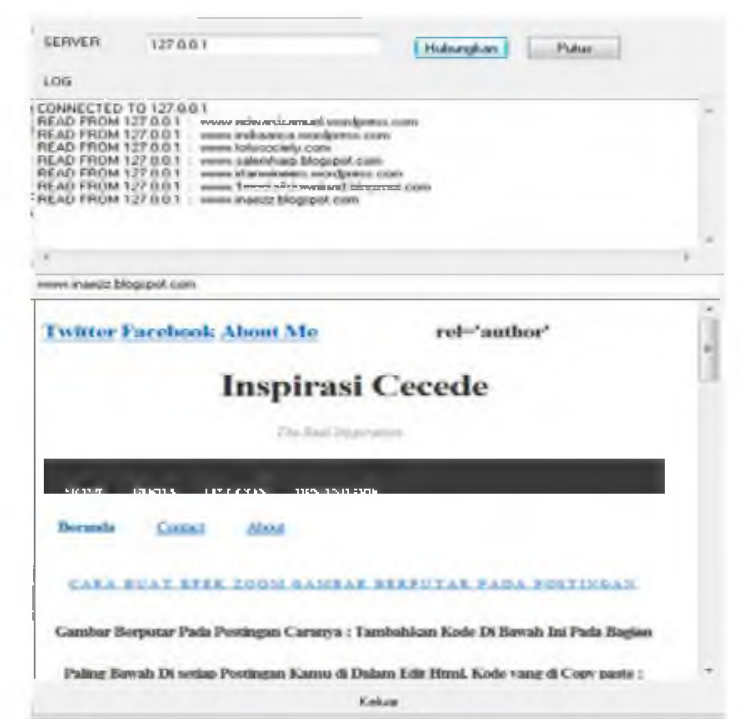

Gambar 4 Tampilan Komputer Client pada PC Client Saat Menerima Pesan

\section{Uji Mengirim Pesan}

Dalam uji mengirim pesan ini, dilakukan uji coba ke beberapa komputer yang terdapat di STTA Yogyakarta. Apabila ingin mengirim pesan, pengguna harus memasukkan alamat IP komputer server dari penerima pesan yaitu komputer client. Agar komputer server dan client terhubung, sehingga pesan akan dapat dikirim dari aplikasi server ke aplikasi client. Setelah pesan berhasil dikirim, maka aplikasi server akan berhenti dan keluar dari aplikasi. Tabel 3 memuat data uji coba pengiriman pesan yang dikirimkan ke komputer PC Client dan lainnya. 


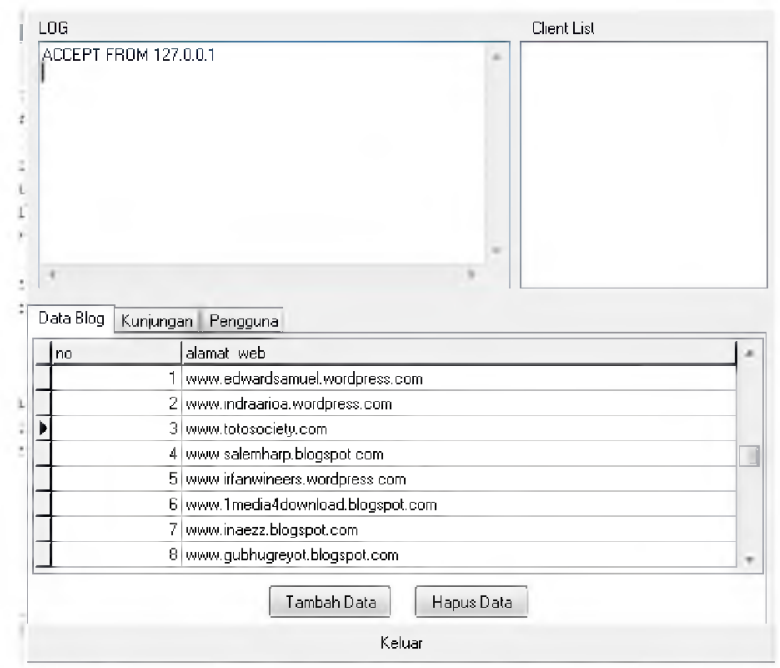

Gambar 5 Aplikasi Server Mengirim Pesan

Tabel 3 Uji Pengiriman Pesan

\begin{tabular}{|c|c|c|c|}
\hline No & Nama Komputer Client & Dikirim & Tidak Dikirim \\
\hline 1 & PC Client 1 & $\sqrt{ }$ & - \\
\hline 2 & PC Client 2 & $\sqrt{ }$ & - \\
\hline 3 & PC Client 3 & $\sqrt{ }$ & - \\
\hline
\end{tabular}

Dari tabel 3 uji coba pengiriman pesan dapat diketahui bahwa semua pesan yang dikirimkan oleh komputer client, dalam hal ini komputer PC Client dan yang lain berhasil mengirimkan pesan ke alamat IP tujuan. Tabel 3 menjelaskan bahwa tanda centang (N) pada tabel dikirim menggambarkan bahwa server sudah mengirim data ke PC Client 1, 2 dan 3.

\section{Uji Fungsi}

Dalam uji fungsi ini dimaksudkan untuk melakukan pengujian terhadap sistem yang dibangun apakah sudah berjalan dengan baik atau belum. Pengujian uji fungsi ini meliputi uji operator dan halaman web yang digunakan sebagai bahan uji coba.

\section{Uji Operator}

Dalam melakukan uji operator ini menggunakan 3 buah sim card dari operator telepon seluler yang sama, yaitu tri (3). Tujuan dari uji operator ini yaitu untuk mengetahui bahwa biaya yang diperlukan untuk mengirim pesan menggunakan operator three merupakan yang termurah (“Setyoadi, Wangsit. 2012"). Tabel 4 menunjukkan perbandingan biaya dari 3 provider yang berbeda.

Tabel 4 Uji Operator

\begin{tabular}{|c|c|c|}
\hline No & Nama Operator & Biaya (Rp.) \\
\hline 1 & Tri & 10.000 \\
\hline 2 & Telkomsel & 50.000 \\
\hline 3 & Axis & 10.000 \\
\hline
\end{tabular}

Dari tabel 4 uji operator dapat diketahui bahwa biaya pengiriman pesan untuk operator merupakan yang termurah. Provider tri (3) merupakan yang termurah karena dengan biaya Rp.10.000,- mendapatkan kuota 200Mb. 


\section{Uji Peringkat Halaman Web}

Dalam melakukan uji peringkat ini menggunakan sebuah situs web yang berfungsi mengukur sebuah situs yang mempunyai jumlah pengunjung dan jumlah halaman yang dibuka oleh seorang pengunjung yaitu histats.com. Selain itu, uji peringkat juga menggunakan alexa.com untuk mengetahui di peringkat berapa situs web yang digunakan untuk uji program yang telah dibangun ini. Hal ini ditunjukkan pada gambar 6

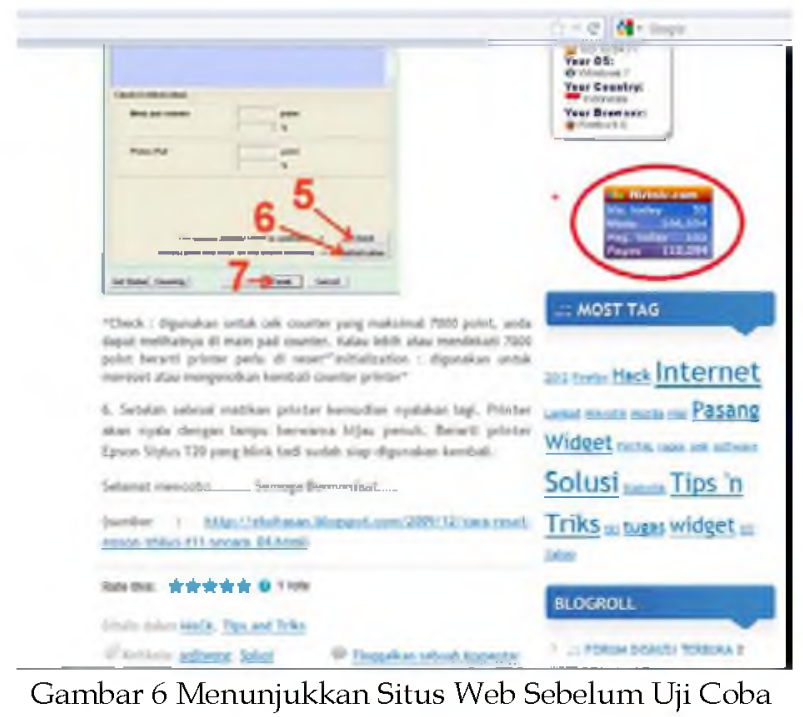

Gambar 6 menunjukkan situs web sebelum di uji coba. Berhasil atau tidaknya hasil dari uji coba ini dilihat dan dipantau dari website Histats.com yang digunakan untuk memantau visitor dan page view, dan Alexa.com yang digunakan untuk memantau peringkat yang didapatkan setelah uji coba. Kedua website tersebut sebagai indikator untuk hasil uji coba program yang dibangun.

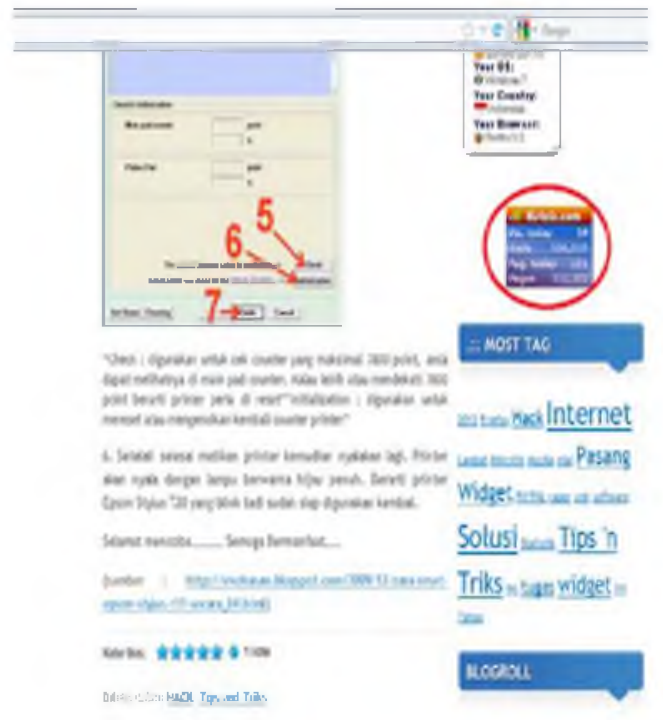

Gambar 7. Menunjukkan Hasil Uji Coba

Gambar 7 merupakan hasil dari uji coba program, hasil diatas menunjukkan bahwa setelah dibuka random 10kali untuk visitor naik 1 dari 106,034 menjadi 106,035 dan untuk page 
view naik 112,294 menjadi 112,312. Visitor hanya naik 1, hal ini kemungkinan histats.com tidak dapat mendeteksi alamat IP yang berbeda-beda.

Ditinjau dari website alexa.com, terdapat situs web yang dapat naik setelah dibuka 30kali dalam sehari dan terdapat beberapa situs web yang tidak naik. Hal ini dikarenakan situs web tersebut terdapat script yang tidak dapat dibuka / diproses oleh browser yang dibangun sendiri.

\section{Analisa Regresi Linier}

Analisa regresi dalam statistika adalah salah satu metode untuk menentukan hubungan sebab-akibat antara satu variabel dengan variable yang lain. Dalam hal ini, sumbu x sebagai jumlah membuka situs web (secara random) dan sumbu y sebagai page view yaitu untuk melihat jumlah halaman sebuah blog yang sudah dibuka oleh pengunjung. Regresi linier ini dibuat menggunakan Microsoft Excel seperti ditunjukkan pada gambar 8.

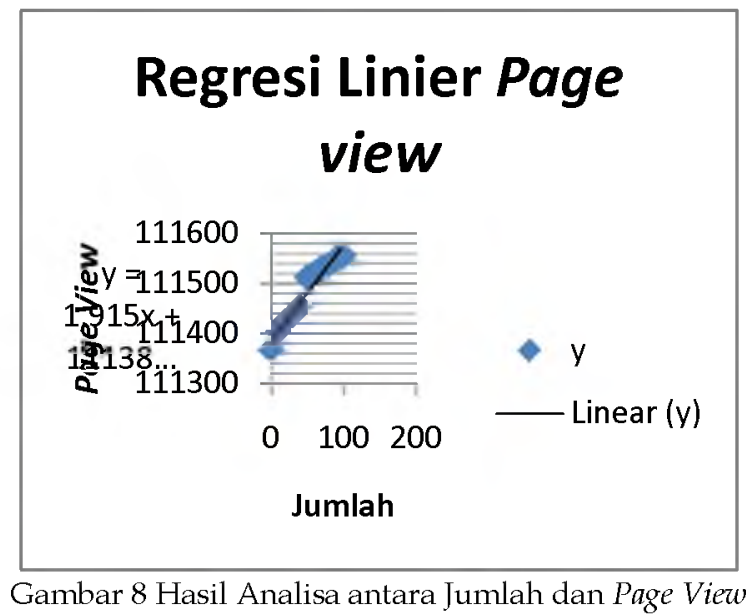

Gambar 8 menjelaskan bahwa menunjukkan grafik keberhasilan kenaikan dalam uji coba aplikasi client dan server untuk mengirim, menerima dan membuka situs web. Pengujian ini dilakukan secara random dalam memonitornya. Ada beberapa halama web yang menunjukkan kenaikkan yang tidak terlalu terlihat. Hal ini disebabkan karena website histats.com tidak mencatat situs web yang dibuka dengan provider yang sama walaupun dengan alamat IP yang berbeda tetapi. Histats hanya mencatat page view-nya dan untuk visitor hanya beberapa saja yang tercatat. Hal ini disebabkan karena histats.com hanya mencatat alamat IP yang berbeda saja untuk page view. Sedangkan untuk visitor, histats.com hanya dapat mencatat dan melihat dari provider yang berbeda walaupun alamat IP berbeda. Regresi linier yang kedua adalah analisa antara jumlah membuka situs web dan visitor seperti ditunjukkan pada gambar 9 . 


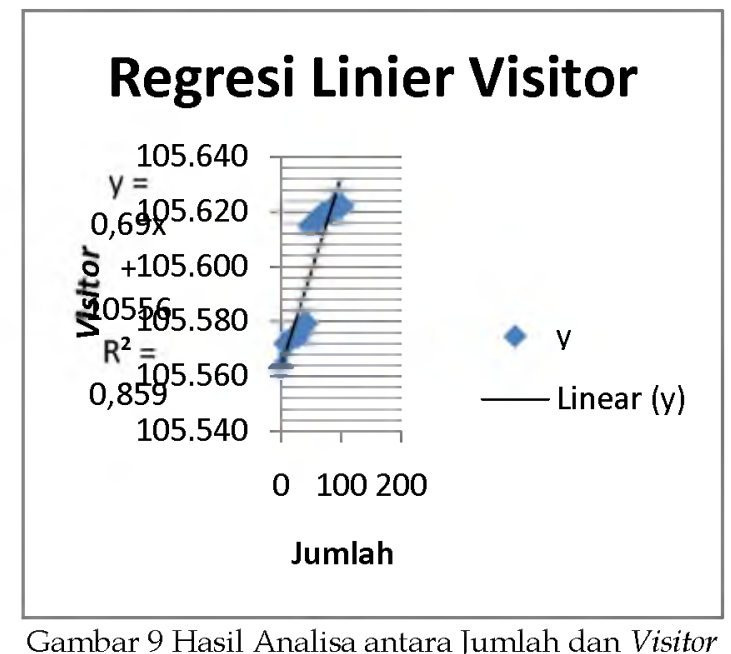

Dari gambar 9 menunjukkan bahwa antara jumlah dalam membuka situs web dan jumlah visitor kurang berhasil dalam hasil uji coba. Hal ini terjadi kemungkinan website histats.com tidak dapat mendeteksi alamat ip yang berbeda dalam provider yang sama. Regresi linier yang ketiga adalah analisa antara jumlah membuka situs web dan alexa.com seperti ditunjukkan pada gambar 10 .

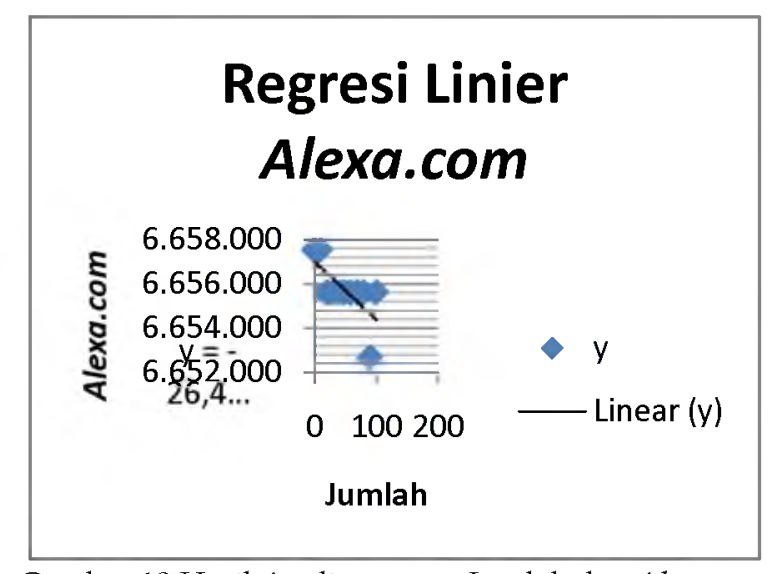

Gambar 10 Hasil Analisa antara Jumlah dan Alexa.com

Dari gambar 10 menunjukkan bahwa antara jumlah dalam membuka situs web dan ranking di website alexa.com kurang berhasil dalam hasil uji coba. Hal ini terjadi website alexa.com akan naik apabila dalam uji coba menggunakan provider yang berbeda-beda dan dalam sehari dibuka 30kali seperti yang ditunjukkan gambar 10 .

\section{Hasil Analisa}

Hasil dari semua percobaan dapat dianalisa dari implementasi dan simulasi percobaan adalah tentang proses mekanisme kerja dari sistem secara keseluruhan. Secara keseluruhan hasil analisa terdiri dari konsep dasar yang dibangun untuk menjadi sebuah sistem dengan apa yang telah sebelumnya.

Langkah-langkah analisa dari hasil percobaan adalah sebagai berikut:

1. Aplikasi server dan aplikasi client dapat saling berkomunikasi dengan menggunakan port yang telah ditentukan oleh aplikasi server.

2. Komputer client terlebih dahulu harus terhubung dengan modem. 
3. Pesan akan dikirimkan ke komputer client yang terhubung, dan apabila ada 2 komputer client yang terhubung maka pesan yang dikirim akan sama dengan pesan yang dikirimkan ke komputer client yang terlebih dahulu terhubung.

4. Pesan yang diterima di aplikasi client akan dibuka di browser yang dibangun di aplikasi client.

Sedangkan analisa dari hasil percobaan adalah sebagai berikut:

1. Aplikasi server berhasil mengirimkan pesan yang dikirim ke aplikasi client.

2. Browser yang dibangun oleh aplikasi client tidak mendukung javascript, sehingga akan terjadi error untuk halaman web yang mengandung javascript. Tetapi tetap dapat diproses oleh browser oleh aplikasi client dengan meng-klik OK.

3. Hasil analisa regresi linier page view menunjukkan bahwa dengan metode TSC halaman web yang dibuka menunjukkan kenaikkan jumlah halaman yang telah terbuka.

4. Hasil analisa regresi linier visitor menunjukkan bahwa dengan metode TSC halaman web yang dibuka menunjukkan kenaikkan jumlah pengunjung yang tidak terlalu terlihat, hal ini dikarenakan histats.com tidak mencatat provider yang sama walaupun alamat IP-nya berbeda-beda.

5. Hasil analisa regresi linier alexa.com menunjukkan bahwa dengan metode TSC halaman web yang dibuka menunjukkan kenaikkan ranking yang tidak terlalu terlihat, hal ini dikarenakan alexa.com tidak mencatat provider yang sama walaupun alamat IP-nya berbeda-beda.

\section{Kesimpulan}

Dari hasil uji coba pada yang dilakukan dapat ditarik beberapa kesimpulan:

1. Aplikasi yang dirancang dan diujicobakan sudah berjalan sesuai dengan tujuan dengan indicator kenaikan jumlah visitor dan page view melalui histats.com.

2. Metode TSC (Together Single Connection) yang digunakan dalam aplikasi sudah berhasil menaikkan ranking blog pada alexa.com dengan minimal jumlah kunjungan 30kali.

3. Jumlah visitor sebuah situs akan bertambah besar saat dikunjungi dengan IP address yang berbeda.

4. Analisa statistik dengan metode regresi linier histats.com dan alexa.com menunjukkan bahwa hasil uji coba berhasil menaikkan kunjungan dan ranking blog.

Selain kesimpulan, penelitian ini juga memiliki saran yang dapat digunakan untuk pengembangan dan penelitian selanjutnya yang terkait dengan penelitian ini. Saran tersebut antara lain:

1. Menggunakan browser yang memiliki fasilitas update javascript dan Macromedia Flash.

2. Penggunaan provider yang berbeda pada aplikasi client diharapkan dapat bertambah kuantitasnya

\section{Referensi}

[1] Kristanto, Andri, Rekayasa Perangkat Lunak, Gava Media Yogyakarta, 2004.

[2] Madcoms, Pemrograman Borland Delphi 7, Andi Offset, Yogyakarta, 2003.

[3] Sutedjo, Budi, Konsep \& Aplikasi Pemrograman Client Server dan SistemTerdistribusi, Andi Offset, 2006. 
[4] Setyoadi, Wangsit, Otomatisasi Penerimaan Dan Pengiriman Pesan Dengan Sistem Terdistribusi Untuk Mendukung Penyebaran Informasi Akademik, Compiler, Volume 1 Nomor 1. Mei 2012.

[5] (22 April 2012) Histats, http://www.histats.com..

[6] (30 April 2012) Master Komputer, http://master-komputer.com/tutorial/41programming/86-socket-programming-delphi.pdf.

[7] (2011) Dhany, http:// dhany.web.id/panduan-seo 